REEL - REVISTA ELETRीNICA DE ENGENHARIA CIVIL $\quad$ Volume 9, No 3, $1-9$

\title{
SUBSTITUIÇÃO RACIONAL DE HIDRÔMETROS EM SISTEMAS DE ABASTECIMENTO DE ÁGUA
}

\section{Rational Substitution of Water Meter on Water Supply Systems}

\author{
Paulo Sérgio Scalize ${ }^{1}$, Wellington Cyro de Almeida Leite ${ }^{2}$, Marcus André Siqueira Campos ${ }^{3}$ \\ Recebido em 18 de agosto de 2014; recebido para revisão em 17 de setembro de 2014; aceito em 27 de setembro \\ de 2014; disponível on-line em 15 de novembro de 2014.
}

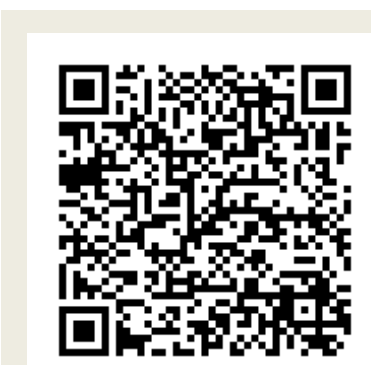

PALAVRAS CHAVE:

Medidor de água;

Perdas aparentes;

Submedição;

Hidrômetro.;

\section{KEYWORDS:}

Water meter;

Apparent loss;

Under-measuremen;

Hydrometer.

RESUMO: O presente trabalho avaliou o efeito da submedição em 862 hidrômetros de uma cidade do interior paulista com 75.000 ligações ativas de água, objetivando a criação de uma proposta para identificar os hidrômetros com pior desempenho metrológico, indicando a sequência de substituição. Para isso, foram avaliados medidores classe metrológica A e B, segregados por fabricante, ano e volume totalizado. Todos os hidrômetros foram submetidos a teste em bancada em três vazões, $15 \mathrm{~L} / \mathrm{h}$ (classe B) ou $30 \mathrm{~L} / \mathrm{h}$ (classe A), $75 \mathrm{~L} / \mathrm{h}$ (classe A e B) e 750L/h (classe A e $B$ ). Os resultados apontaram que $37,1 \%$ foram reprovados registrando leituras menores que a leitura de referência, com submedição variando de $-0,7$ a $31,1 \%$. Foi observado que alguns hidrômetros mais antigos estavam com melhores desempenhos metrológicos que os mais novos, podendo, caso fosse realizada uma substituição sem critérios, haver aumento de perda aparente com uma redução de receita ao invés de benefícios. Este estudo possibilitou a criação de uma sequência de grupos de hidrômetros que apresentou menor desempenho metrológico, e sua substituição acarretará um aumento no volume micromedido, reduzindo o índice de perdas aparente e, consequentemente aumentando o volume faturado.

ABSTRACT: This study evaluated the effect of under-metering in 862 water meters in a countryside city of São Paulo State, with 75,000 active water connections. It was evaluated metrological class A and B water meters, separated by manufacturer, year and totalized volume. All water meters were subjected to bench tests in three flows, $15 \mathrm{~L} / \mathrm{h}$ (class B) or $30 \mathrm{~L} / \mathrm{h}$ (class A), $75 \mathrm{~L} / \mathrm{h}$ (class A and B) and 750L/ h (A and $B$ class). The results showed that $37.1 \%$ were disapproved by registering reading lower than the reference, with sub-metering ranging from -0.7 to $31.1 \%$. It was observed that some older water meters had better metrological performances than the newest ones, and if a replacement without criteria be held, it may result increase in an apparent losses with a reduction of incoming rather than benefits. This study enabled the creation of a sequence of groups of lowest water meter metrological performance, and its replacement will result in an increase in micromeasured volume, reducing the rate of apparent losses and, consequently, increasing the amount billed.

* Contato com os autores:

${ }^{1}$ e-mail :pscalize.ufg@gmail.com

(P. S. Scalize )

Biomédico e Eng. Civil, Professor Dr. da Escola de Engenharia Civil da Universidade Federal do Goiás - EEC/UFG.

2e-mail : wcyro@uol.com.br (W. C. A. Leite )

Eng. Civil, Professor Dr. da Faculdade de Engenharia de Guaratinguetá da Universidade Estadual Paulista Júlio de Mesquita Filho.

${ }^{1}$ e-mail :marcuscampos@gmail.com (M. A. S. Campos)

Eng. Civil, Professor Dr. da Escola de Engenharia Civil da Universidade Federal do Goiás - EEC/UFG.
\end{abstract}




\section{INTRODUÇÃO}

As perdas nos sistemas de abastecimento de água estão próximas a 40\%. Segundo dados coletados pelo SNIS em 2011 (SNIS, 2013), a média do valor reportado por 4.941 municípios brasileiros está em 38,8\%, o que evidencia que qualquer ação a ser tomada contribuirá para a redução desse índice. Morais e Almeida (2006) propõem a aplicação de um modelo para tomada de decisão, utilizando aspectos financeiro, técnico, ambiental e social, relatam ainda que as empresas estão "jogando dinheiro fora" por falta de um gerenciamento adequado. Citam ainda que entre os problemas estão os hidrômetros.

Morais et al. (2010), empregando um modelo multicritério para priorizar as áreas críticas de perdas de uma cidade, utilizam como parâmetros os volumes entregues e micromedidos em conjunto com a vida útil dos equipamentos e adequada aferição entre outros. A utilização dos dados da vida útil de um equipamento pode ser um dado muito variável, pois existem grandes variações de qualidade entre as marcas existentes no mercado, possibilitando que um medidor mais antigo seja mais eficiente que um mais recente.

Visando o combate às perdas aparentes, o parque de hidrômetros deve ser submetido à manutenção preventiva ativa, com avaliação criteriosa dos hidrômetros a serem substituídos. $\mathrm{Na}$ maior parte dos municípios, a prática das empresas de saneamento é proceder à substituição dos hidrômetros de idade superior a cinco anos ou ainda que possuam volume de medição totalizado superior a $2.000 \mathrm{~m}^{3}$. Este critério não é o melhor, pois o desempenho metrológico não é avaliado, sendo simplesmente seguidas práticas anteriores baseadas em uma interpretação errônea do artigo 8ㅇ da Portaria 246 do INMETRO (2000) que diz que verificações periódicas devem ser efetuadas nos hidrômetros em uso, em intervalos não superiores a 5 anos. Fiorin e Scaratti (2012) relatam em sua pesquisa no parque de hidrômetro da cidade de Joaçaba-SC, que a melhor prática para sua gestão é a substituição por volume totalizado e não pelo tempo de instalação.
No Brasil, grande parte das residências utiliza reservatório domiciliar, controlado por torneira de boia convencional o que influencia significativamente a submedição. Pereira e Ilha (2008), concluíram em sua pesquisa que a instalação de torneiras de boias de alta vazão eliminaria a submedição. Deve-se, no entanto, tomar preocupações relação à especificação do hidrômetro, para que sua vazão ideal de funcionamento não seja excedida.

Piechnicki et al. (2011), relatam em seu trabalho que as perdas causadas pelos erros nos hidrômetros representam uma parcela considerável dentre as perdas aparentes, afetando diretamente o índice de perdas de água e de faturamento. $O$ dimensionamento e a manutenção permanente são fundamentais para garantir o correto funcionamento do hidrômetro. Sanchez et al. (2000), estudando o parque de hidrômetros da cidade de Juazeiro-BA, relata que a submedição para hidrômetros novos é de $8 \%$, destacando que pode não ser economicamente viável a substituição em locais de baixo consumo, uma vez que nestes é cobrada tarifa mínima.

Os valores encontrados por esses autores chegam até $65,6 \%$ de submedição, a depender da faixa de consumo, do tipo de hidrômetro empregado e da idade de instalação, orientando que um plano de substituição dos hidrômetros pode gerar um grande retorno financeiro. Fonseca e Coelho (2009) relataram que as perdas por submedição em uma concessionária podem variar entre 10 e $30 \%$ e, em sua pesquisa recomendam a implantação de um programa de manutenção dos hidrômetros baseados em estudos de engenharia econômica associada à avaliação sistemática da precisão do parque de hidrômetros. Scalize e Leite (2012) citam em seu trabalho que a política tarifária empregada na maioria dos órgãos responsáveis pelo abastecimento e cobrança pelo uso da água no Brasil, utilizam a cobrança por faixa, com efeito "cascata". Portanto, o cliente que consome mais é enquadrado em faixas superiores onde o custo do volume utilizado é maior. Dessa forma, qualquer valor recuperado nas faixas superiores de consumo representa um retorno financeiro 
superior àqueles relativos aos valores das perdas físicas, tais como vazamentos nas redes de distribuição, para os quais a redução dessas perdas tem um ganho relativo somente ao custo de produção, além de ganhos ambientais.

\section{OBJETIVOS}

O presente trabalho apresenta uma proposta de metodologia para identificar os hidrômetros com o pior desempenho metrológico, os quais devem ser substituídos.

\section{METODOLOGIA}

Foram examinados 862 hidrômetros, de classe $A$ e $B$, retirados da rede de distribuição de uma cidade do interior paulista com aproximadamente 75.000 ligações ativas de água. Os hidrômetros foram segregados por fabricantes e por três faixas de leituras totalizadas, sendo de 0 a $1000 \mathrm{~m}^{3}$, de 1001 a $2000 \mathrm{~m}^{3}$ e acima de $2001 \mathrm{~m}^{3}$. Todos os hidrômetros foram submetidos a teste em bancada em três vazões, $15 \mathrm{~L} \mathrm{~h}^{-1}$ (classe $\mathrm{B}$ ) ou $30 \mathrm{~L} \mathrm{~h}^{-1}$ (classe A), $75 \mathrm{~L} \mathrm{~h}^{-1}$ (classe A e B) e $750 \mathrm{~L} \mathrm{~h}^{-1}$ (classe $A$ e $B$ ), onde os erros máximos admissíveis baseiam-se no item 8.5 da Portaria 246 (INMETRO, 2000), sendo $\pm 10 \%$ entre Qmin, inclusive e Qt, exclusive, e $\pm 5 \%$ entre $\mathrm{Qt}$, inclusive e Qmax, inclusive. Foram avaliados hidrômetros de seis diferentes marcas, com data de fabricação compreendida entre 1995 e 2006.

Os erros apontados para cada uma das três vazões em que foram submetidos os 862 hidrômetros foram tabelados, sendo efetuada uma média aritmética para todos os dados de um lote de hidrômetros de mesmo fabricante, faixa de volume totalizado e ano de fabricação. Os resultados foram obtidos separadamente para os hidrômetros aprovados e para os reprovados marcando a menos. Neste estudo não foi encontrado nenhum hidrômetro marcando acima do valor de referência.

O volume submedido para cada hidrômetro foi determinado utilizando o perfil de consumo da cidade estudada (Tabela 1), obtido em estudos realizados por empresa contratada. Este perfil pode ser obtido utilizando registrador de vazão (logger) instalado nas residências. O consumo médio residencial foi calculado dividindo-se o volume micromedido pelo número de ligações residenciais, sendo de 19,8 $\mathrm{m}^{3}$ mês $^{-1}$.

Foi realizado um cálculo financeiro para o valor recuperado para cada situação. Para isso, foi levada em consideração que a cobrança é realizada de forma progressiva, escalonamento ou também dita "cascata", ou seja, em faixas de consumo menores, o valor do metro cúbico é menor e, à medida que as faixas ficam maiores, o valor do metro cúbico é superior quando comprados às faixas de consumos menores. Esse tipo de cobrança é verificado nas concessionárias brasileiras conforme constado por Campos et al. (2006), que diz ainda que esse escalonamento é justo e permite a quem consome mais pagar valores do metro cúbico maior, mas alerta que as faixas não devem ser demasiadamente longas e não curtas, sendo $10 \mathrm{~m}^{3}$ a mais utilizada no Brasil. Nesse trabalho foi utilizado o valor de $\mathrm{R} \$$ 3,25 para cada metro cúbico consumido acima de $20 \mathrm{~m}^{3}$, que é o consumo médio da cidade de estudo, bem como o valor cobrado.

\section{RESULTADOS E DISCUSSÕES}

O estudo evidenciou que dos 862 hidrômetros analisados, 37,1\% foram reprovados registrando leituras abaixo do valor de referência (Tabela 1). O índice de reprovação por modelo de hidrômetro, fabricante e volume totalizado está descrito na Figura 1.

\section{TABELA 1: Perfil de consumo da cidade estudada e valores de consumo utilizados na pesquisa.}

\begin{tabular}{ccccc}
\hline Faixa de leitura (L) & 0 a 30 & 30 a 75 & 75 a 750 & $>750$ \\
\hline Consumo (\%) & 14,44 & 18,74 & 59,45 & 7,37 \\
\hline Consumo utilizado na pesquisa (\%) & 14,44 & 18,74 & 66,82 \\
\hline
\end{tabular}




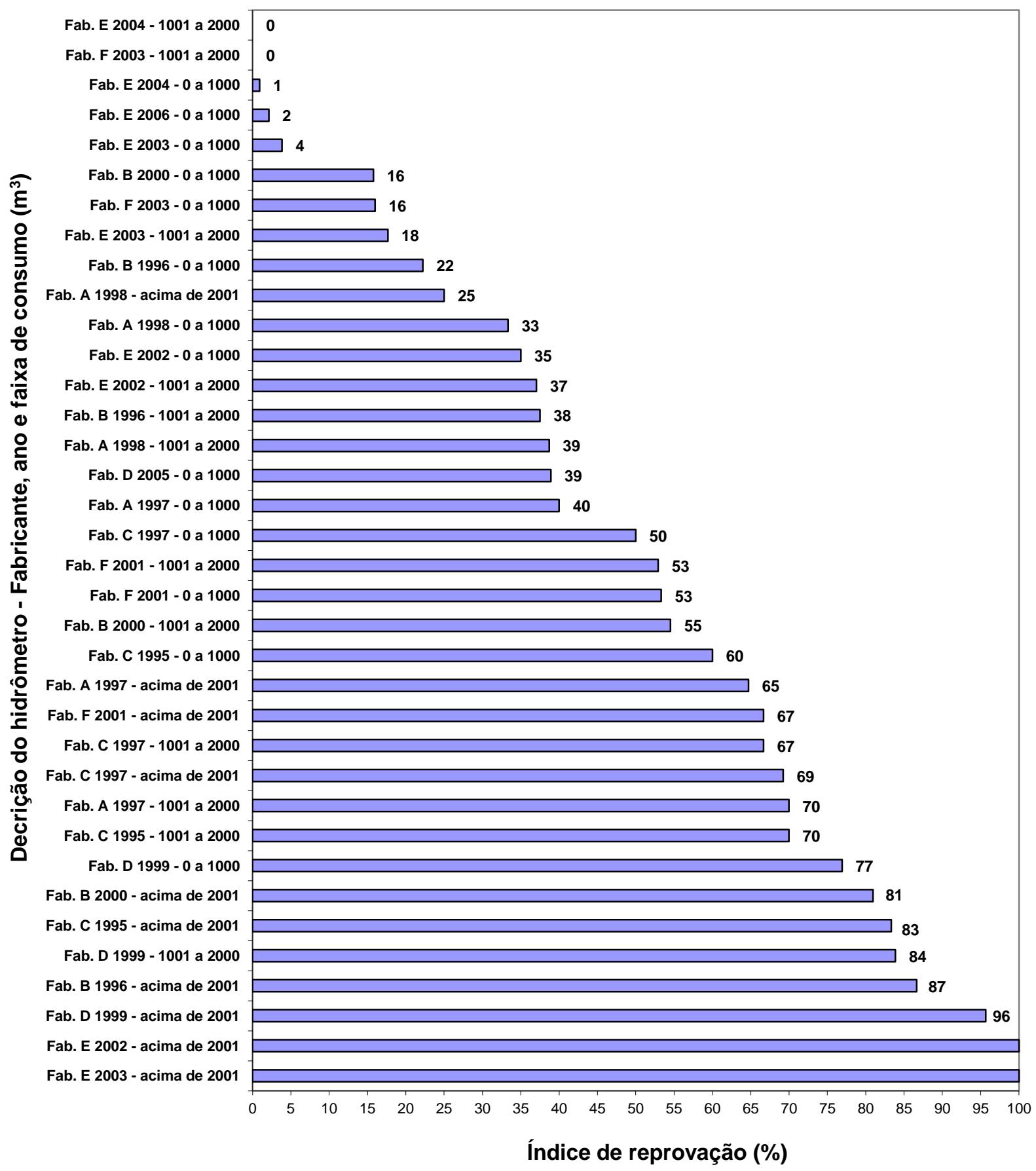

FIGURA 1: Índice de reprovação em ordem crescente dos hidrômetros estudados.

Os lotes de hidrômetro que apresentaram um menor desempenho metrológico, ou seja, aqueles hidrômetros em que o volume registrado foi inferior ao volume consumido, foram os do fabricante $D$ instalados em 1999 e com faixa de volume totalizado acima de $2001 \mathrm{~m}^{3}$, seguidos da faixa de 1001 a $2000 \mathrm{~m}^{3}$ do mesmo ano e fabricante. O volume médio incrementado devido à substituição destes hidrômetros deve ser da ordem de $23 \%$ e $30 \%$, respectivamente. Caso fosse possível substituir apenas os hidrômetros que apresentassem uma redução do volume micromedido ao longo do tempo, o volume incrementado seria bem próximo ao obtido pela substituição de todos os hidrômetros de mesmo ano e fabricante, visto que o índice de reprovação foi de $84 \%$ e $96 \%$. Nesta situação, a vantagem obtida com a implantação de um programa seria mínima. No entanto, estes hidrômetros são de 1999 e 
certamente com a implantação de um programa os hidrômetros com problemas teriam sido substituídos já há mais tempo.

A troca indiscriminada pode trazer resultados negativos ao invés de benefícios, ou seja, ao invés do volume aumentar pode haver uma redução ou ainda não exercer nenhuma influência. Esta condição pode ser observada na Tabela 2 (em anexo), pois os hidrômetros dos fabricantes B (1996), A (1998) e D (2005) com faixa de volume totalizado entre 0 e $1000 \mathrm{~m}^{3}$, teriam o volume incrementado de - 0,7\%, - 0,6\% e - 0,5\% respectivamente para os hidrômetros trocados que seriam considerados aprovados. Esse mesmo fato foi detectado para os fabricantes B (2000) e
F (2001), com volume totalizado acima de 2001 $\mathrm{m}^{3}$, onde o incremento seria de $-0,2 \%$ e $-0,4 \%$, respectivamente.

Na Figura 2 pode ser observado que a substituição de um determinado hidrômetro pode não ser vantajosa, visto que a porcentagem do volume recuperado seria pequena para tal investimento. Como exemplo, para o hidrômetro do Fab. E - 2003, na faixa de leitura de 0 a 1000 $\mathrm{m}^{3}$. A substituição de todos estes hidrômetros resultaria em um acréscimo de $1,7 \%$, enquanto que apenas com a substituição dos reprovados este acréscimo seria de $14,5 \%$. Para este caso a porcentagem de reprovação foi de 16\%, num universo de 25 hidrômetros analisados.

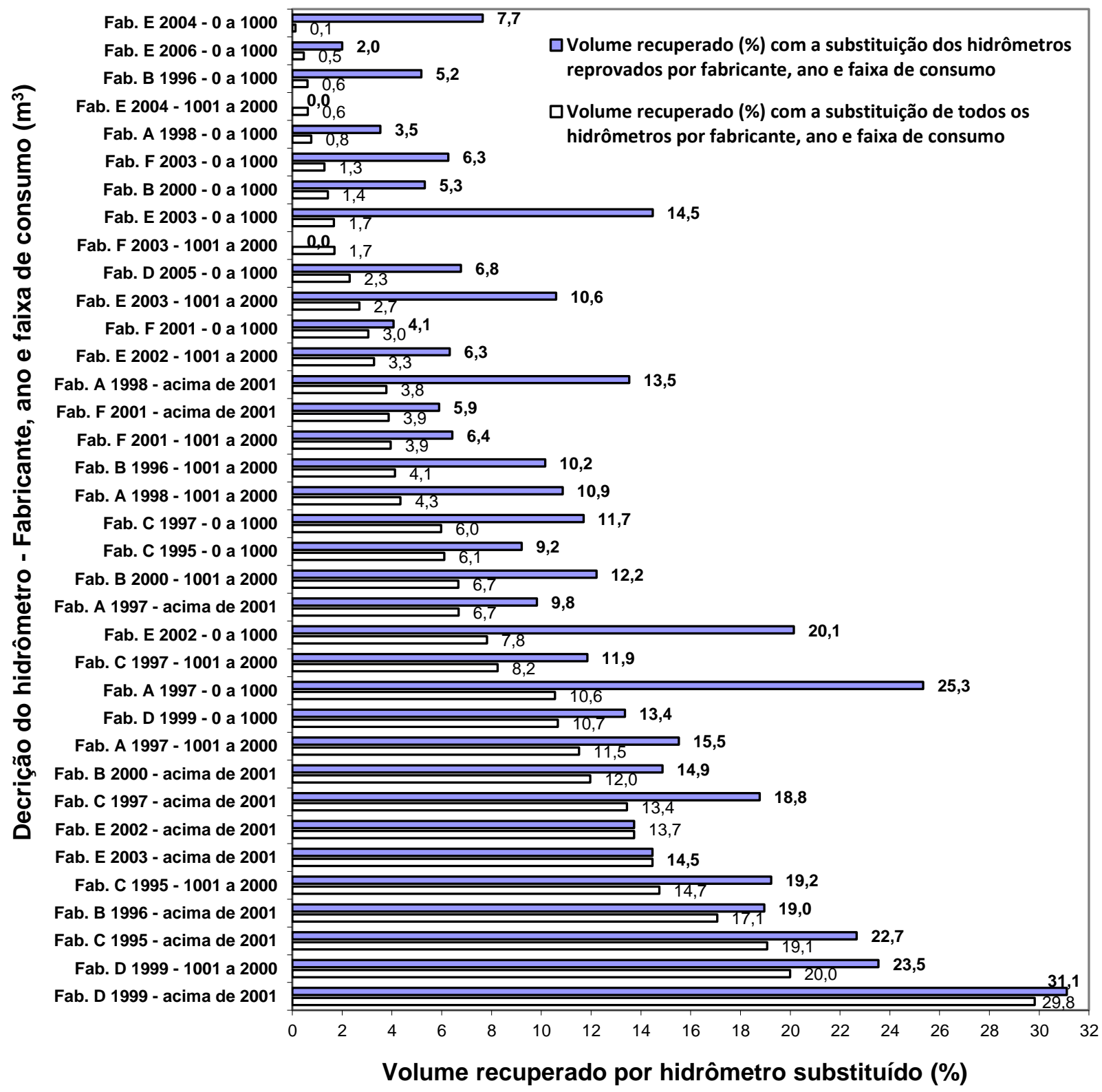

FIGURA 2: Comparação entre o volume recuperado, por hidrômetro substituído, considerando todos os hidrômetros ou apenas os reprovados. 
Outra situação que deve ser observada é relativa aos hidrômetros do Fab. A - 1997 e do Fab. E - 2002, todos na mesma faixa de consumo entre 0 e $1000 \mathrm{~m}^{3}$, onde o índice de reprovação foi de $40 \%$ e $35 \%$ (Figura 1). As trocas destes hidrômetros acarretariam um acréscimo de 10,6 e $7,8 \%$, respectivamente (Figura 2 ), enquanto, caso fosse realizada a substituição, apenas dos hidrômetros registrando abaixo do valor de referência, o ganho seria $25,3 \%$ e $20,1 \%$, ou seja, muito maior.
Em termos financeiros, para 0 hidrômetro do Fab. A - 1997 na faixa de 0 a 1000 $\mathrm{m}^{3}$, considerando o consumo médio de $20 \mathrm{~m}^{3}$ mês ${ }^{1}$, e o valor de cada $1 \mathrm{~m}^{3}$, acima deste consumo até $30 \mathrm{~m}^{3}$ mês $^{-1}$, de $\mathrm{R} \$$ 3,25 (O órgão responsável cobra o consumo por faixas em cascata), resultaria em um acréscimo, por hidrômetro substituído, de $\mathrm{R} \$ 6,78$ ou de $\mathrm{R} \$ 16,28$ caso fossem substituídos apenas os reprovados, um aumento de $140 \%$. Os incrementos de receita podem ser observados na Figura 3 e Tabela 2 (em anexo).

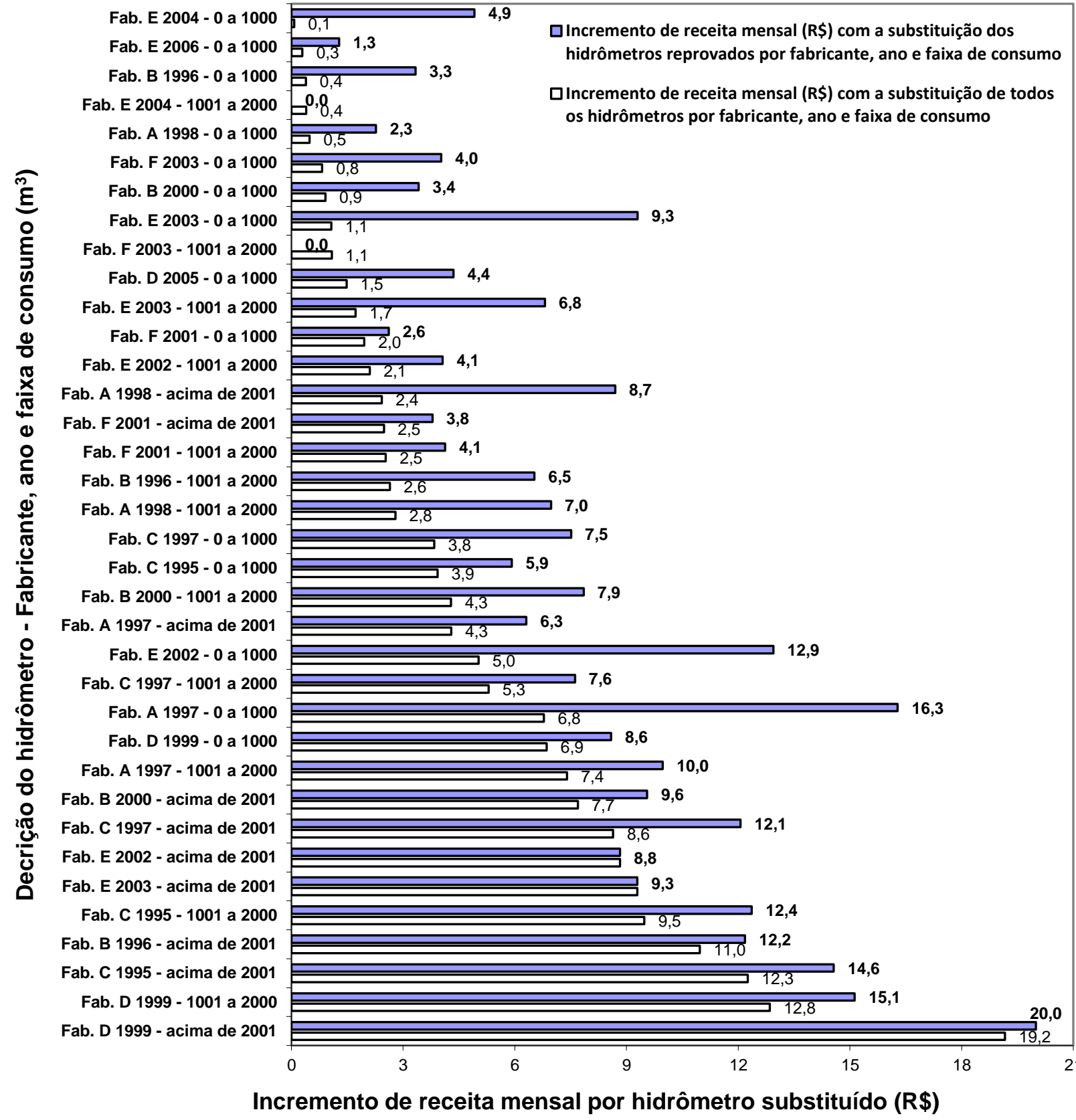

FIGURA 3: Incremento de receita mensal para cada hidrômetro substituído. Pode ser observado que, substituindo apenas os hidrômetros reprovados, os valores recuperados serão maiores, quando comparados com a substituição de todos os hidrômetros de um mesmo fabricante, ano e faixa de leitura. 
Na Figura 4 pode ser observado que após a substituição de um hidrômetro do Fab. D - 1999, na faixa de 1001 a $2000 \mathrm{~m}^{3}$, houve um grande aumento de consumo. Este hidrômetro foi reprovado marcando $-100 \% Q_{\min },-99 \% Q_{\text {tran }}$ e $14,1 \% Q_{n}$. Neste caso o hidrômetro novo registra uma média diária de $787 \mathrm{~L} \mathrm{dia}^{-1}$, enquanto que o antigo registrava uma média de $340 \mathrm{~L} \mathrm{dia}^{-1}$. Este aumento está além do esperado de acordo com a Figura 2, ou seja, um aumento de $31,1 \%$.

Na Figura 5 pode ser observado que após a substituição de um hidrômetro do Fab. B - 1996, na faixa acima de $2001 \mathrm{~m}^{3}$, houve uma redução no volume registrado em $5 \%$. O hidrômetro retirado estava registrando $+3,5 \% Q_{\min },-2,0 \% Q_{\text {tran }}$ e $-4,7 \%$ $Q_{n}$, ou seja, estava marcando corretamente. Neste caso o hidrômetro novo passou a registrar um volume médio $871 \mathrm{~L} \mathrm{dia}^{-1}$, enquanto que o antigo registrava uma média de $916 \mathrm{~L} \mathrm{dia}{ }^{-1}$. Esta redução está fora do esperado de acordo com a Tabela 2 para hidrômetro aprovado. Neste caso, o hidrômetro novo (Fab. D - 2005, na faixa de 0 a $1000 \mathrm{~m}^{3}$ ) foi retirado e ficou constatado que estava registrando leitura abaixo do valor de referência. O hidrômetro atual (Fab. E - 2006) está registrando um volume médio de $1000 \mathrm{~L}_{\text {dia }}{ }^{-1}$, significando um aumento de $9,1 \%$, próximo ao valor de 4,8\% esperado de acordo com a Tabela 2.

Vale ressaltar que os valores apresentados não levam em consideração o erro de medição de um hidrômetro novo, ou seja, o volume recuperado deverá ser um pouco menor, visto que um hidrômetro novo pode apresentar um pequeno erro, para o perfil de consumo considerado, de até 2,4\%. Este valor deve aumentar com o tempo, podendo chegar a 5,7\%, e o hidrômetro ainda ser considerado aprovado.

Devido à inexistência, no órgão responsável pelo gerenciamento do parque de hidrômetros, de um programa para substituir apenas os hidrômetros com queda no desempenho, foi estabelecida uma sequência que é apresentada na Figura 2, onde está sendo considerado o critério do maior volume recuperado como prioridade, pois a relação custo/benefício é maior.

$\mathrm{Na}$ Tabela 2 (em anexo) estão contidos todos os valores obtidos com o trabalho realizado. Os valores estão em ordem crescente da menor para a maior porcentagem de volume recuperado por hidrômetro substituído, considerando a substituição de todos os hidrômetros por ano, fabricante e volume totalizado.

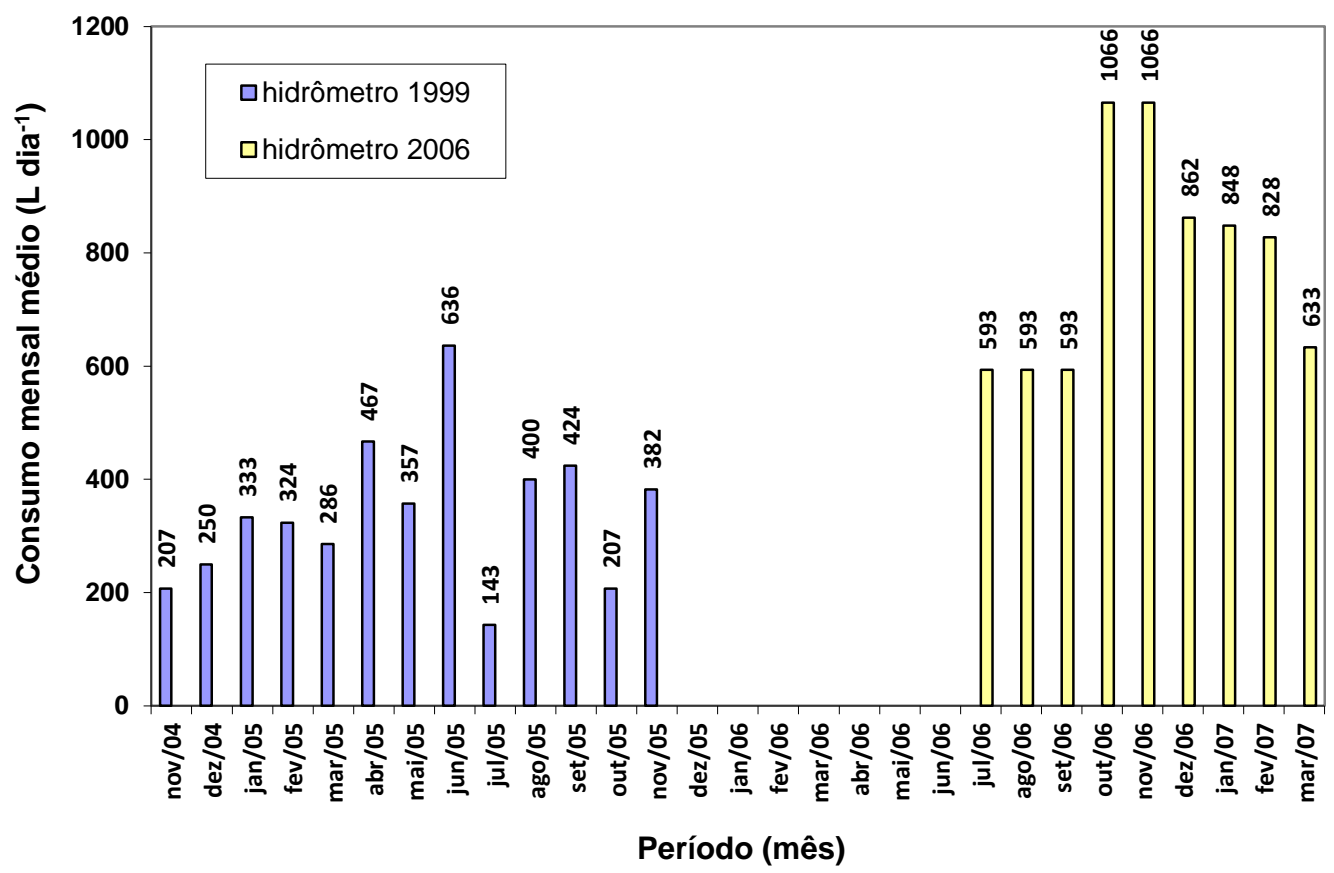

FIGURA 4: O hidrômetro ano 1999 foi reprovado marcando $-100 \% Q_{\min },-99 \% Q_{\text {tran }}$ e $-14,1 \% Q_{n}$. Após substituição do hidrômetro o consumo aumentou de uma média $340 \mathrm{~L} \mathrm{dia}^{-1}$ para $787 \mathrm{~L} \mathrm{dia}^{-1}$. 


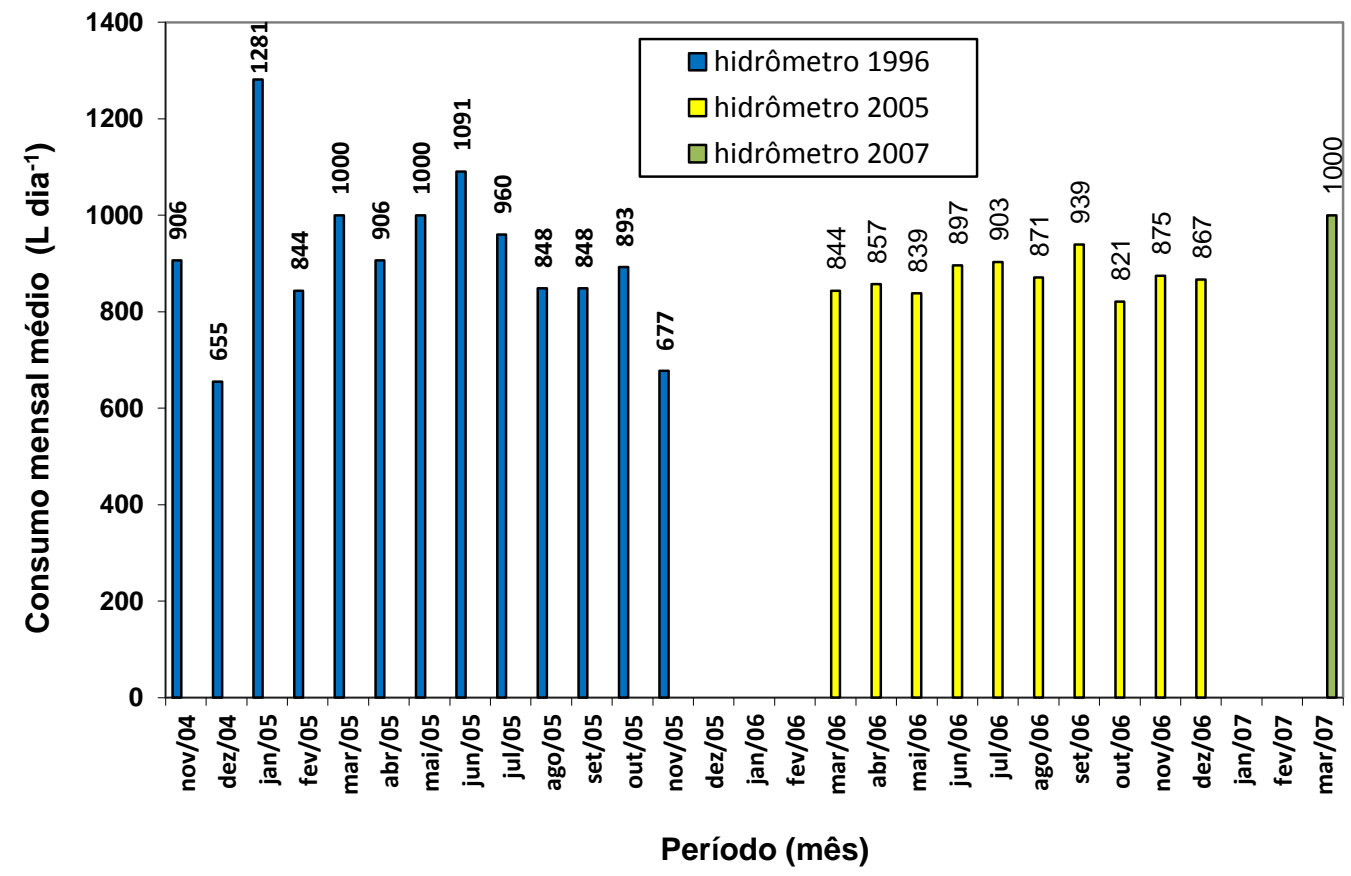

FIGURA 5: O hidrômetro ano 1996 foi aprovado marcando $+3 \% Q_{\min },-2 \% Q_{\operatorname{tran}}$ e $-4,7 \% Q_{n}$. Após substituição do hidrômetro o consumo diminuiu de uma média $916 \mathrm{~L} \mathrm{dia}^{-1}$ para $817 \mathrm{~L} \mathrm{dia}^{-1}$. Voltou a aumentar após instalação de um novo medidor.

\section{CONCLUSÃO}

O presente trabalho permitiu concluir que é necessária a implantação de um programa para análise do desempenho metrológico dos hidrômetros instalados, possibilitando a troca pontual dos medidores com submedição, pois os resultados encontrados variaram de - 0,7 a 31,1\%. O hidrômetro com pior desempenho metrológico foi o do Fab. D - 1999 com volume totalizado acima de $2001 \mathrm{~m}^{3}$, seguido pelo hidrômetro do mesmo fabricante com volume entre 1001 e 2000 $\mathrm{m}^{3}$, representando uma submedição de 29,8 e $20,0 \%$ respectivamente para todo o lote. Pode-se concluir também que hidrômetros mais novos (Fab. D - 2005), estão em piores condições que os hidrômetros do Fab. B - 1996, muito mais antigo. Isto fez com que os critérios de aceitação de hidrômetros novos fossem revistos e implementados novos testes para recebimento (Teste de desgaste acelerado - Fadiga).

Este estudo possibilitou a criação de uma sequência de grupos de hidrômetros que apresentou pior desempenho metrológico, sendo que sua substituição acarretará um aumento no volume micromedido, reduzindo o índice de perdas aparente e, consequentemente aumentando o volume faturado.

\section{REFERÊNCIAS BIBLIOGRÁFICAS}

CAMPOS, M.A.S; RIBEIRO JUNIOR, L.U.; POTIER, A.C.; LUCA, D.M.P.; ILHA, M.S.O. Avaliação da estrutura tarifária brasileira para residências unifamiliaresaspectos quantitativos. In: Encontro Nacional de Tecnologia no Ambiente Construído, $11^{\circ}$, 2006, Santa Catarina. Anais eletrônicos. Porto Alegre-RS.

INMETRO (Instituto Nacional de Metrologia, Normalização e Qualidade Industrial). Portaria 246 de 17 de outubro de 2000.

FIORIN, A.F.; SCARATTI, D. Avaliação da vida útil dos hidrômetros adotados pelo SIMAE de Joaçaba-SC. In: Exposição de Experiências Municipais de Saneamento, 16ạ, 2012. Anais eletrônicos, Maringá-PR: ASSEMAE.

FONSECA, P.; COELHO, A.C. Manutenção de hidrômetros - um problema econômico. In: Congresso Brasileiro de Engenharia Sanitária e Ambiental, 25ạ, 2009. Anais eletrônicos, Recife-PE: ABES.

MORAIS, D.C.; ALMEIDA, A.T. Modelo de decisão em grupo para gerenciar perdas de água. Pesquisa Operacional, Rio de Janeiro, v. 26, n. 3, 2006, p. 567584. 
MORAIS, D.C.; CAVALCANTE, C.A.V.; ALMEIDA, A.T. Priorização de áreas de controle de perdas em redes de distribuição de água. Pesquisa Operacional, Rio de Janeiro, v. 30, n. 1, 2010, p.15-32.

PEREIRA, L.G., ILHA, M.S.O. Avaliação da submedição de água em edificações residenciais de interesse social localizadas em Campinas. Ambiente Construído, Porto Alegre, v. 8, n. 2, 2008, p-7-21.

PIECHNICKI, A.S.; KOVALESKI, J.L.; SOUZA, M.V.; PIECHNICKI, F.; BARAN, L.R. Utilização da metodologia de análise e solução de problemas na redução das perdas de água: Um estudo de caso na SANEPAR. Revista de Engenharia e Tecnologia, v. 3, n. 2, 2011, p. 90-99.

SANCHEZ, J.G.; MOTTA, A.S.; ALVES, W.C. Estimativa de volume de água não medido em ligações residenciais por perda de exatidão nos hidrômetros, na cidade de Juazeiro - BA. In: Congresso Interamericano de Engenharia Sanitária e Ambiental, 27ạ, 2000, Porto Alegre. Anais eletrônicos. Porto Alegre-RS: ABES.

SCALIZE, P.S.; LEITE, W.C.A. Variação na micromedição do consumo de água no funcionamento correto e reversível do hidrômetro. Revista Eletrônica de Engenharia Civil, v. 6, n. 1, 2012, p. 9-15.

SNIS (2013). Sistema Nacional de Informação sobre Saneamento. Diagnóstico dos Serviços de Água e Esgoto 2011. Disponível em <http://www.snis.gov.br>. Acessado em 16 de fev. 2014. 
TABELA 2: Descrição dos medidores, faixas de consumo e os resultados obtidos na verificação do desempenho metrológico. Os valores estão em ordem crescente de volume recuperado por hidrômetro, considerando a substituição de todos os hidrômetros de um determinado fabricante, ano e faixa de volume totalizado.

\begin{tabular}{|c|c|c|c|c|c|c|c|c|c|c|c|c|c|c|c|c|c|c|c|c|c|c|c|c|c|c|c|c|c|c|c|c|}
\hline \multirow{2}{*}{ Fabricante/anolfaixa $\left(\mathrm{m}^{3}\right)$} & \multicolumn{8}{|c|}{ Total } & \multicolumn{9}{|c|}{ Aprovados } & \multicolumn{9}{|c|}{ Reprovados } & \multicolumn{3}{|c|}{$\begin{array}{l}\text { Vol. recuperado por hidrômetro } \\
\text { substituído (\%) }\end{array}$} & \multicolumn{3}{|c|}{$\begin{array}{c}\text { Valor recuperado } \\
\text { (R\$ mensal/hidrômetro) }\end{array}$} \\
\hline & Qde & $\min$ & tran & máx & $\min$ & $\operatorname{tran}$ & máx & total & $\mathrm{n}^{0}$ & & $\min$ & $\operatorname{tran}$ & máx & & & & total & $n^{0}$ & & $\min$ & $\operatorname{tran}$ & máx & $\min$ & $\operatorname{tran}$ & máx & total & Total & Aprov. & Reprov & Total & Aprov. & Reprov. \\
\hline b. E 2004 - 0 a 1000 & 107 & $-0,4$ & $-0,7$ & 0,1 & 0,0 & 0,0 & 0,0 & 0,0 & 106 & 99 & $-0,3$ & $-0,6$ & 0,2 & 0,0 & 0,0 & 0,0 & 0,0 & 1 & 1 & $-10,4$ & $-8,2$ & $-6,9$ & 0,3 & 0,3 & 0,9 & 1,5 & 0,1 & 0,1 & 7,7 & 0,08 & 0,03 & 4,92 \\
\hline D. E 2006 - 0 a 1000 & 47 & $-3,7$ & $-1,5$ & 0,5 & 0,1 & 0,1 & $-0,1$ & 0,1 & 46 & 98 & $-3,5$ & $-1,5$ & 0,5 & 0,1 & 0,1 & $-0,1$ & 0,1 & 1 & 2 & $-12,6$ & $-1,8$ & 0,2 & 0,3 & 0,1 & 0,0 & 0,4 & 0,5 & 0,4 & 2,0 & 0,30 & 0,27 & 1,28 \\
\hline b. B $1996-0$ a 1000 & 9 & $-3,8$ & $-0,4$ & 0,0 & 0,1 & 0,0 & 0,0 & 0,1 & 7 & 78 & 3,2 & 1,0 & 0,1 & $-0,1$ & 0,0 & 0,0 & $-0,1$ & 2 & 22 & $-28,5$ & $-5,5$ & $-0,2$ & 0,8 & 0,2 & 0,0 & 1,0 & 0,6 & $-0,7$ & 5,2 & 0,39 & $-0,45$ & 3,33 \\
\hline D. E 2004 - 1001 a 2000 & 12 & $-1,5$ & $-1,2$ & $-0,3$ & 0,0 & 0,0 & 0,0 & 0,1 & 12 & 100 & $-1,5$ & $-1,2$ & $-0,3$ & 0,0 & 0,0 & 0,0 & 0,1 & 0 & 0 & & - & - & - & - & - & - & 0,6 & 0,6 & - & 0,40 & 0,40 & - \\
\hline b. A $1998-0$ a 1000 & 15 & $-5,2$ & 0,4 & $-0,1$ & 0,1 & 0,0 & 0,0 & 0,1 & 10 & 67 & 1,4 & 2,2 & 0,0 & 0,0 & $-0,1$ & 0,0 & $-0,1$ & 5 & 33 & $-18,5$ & $-3,2$ & $-0,5$ & 0,5 & 0,1 & 0,1 & 0,7 & 0,8 & $-0,6$ & 3,5 & 0,49 & $-0,41$ & 2,27 \\
\hline o. F 2003 - 0 a 1000 & 25 & $-7,9$ & 1,1 & $-0,6$ & 0,2 & 0,0 & 0,1 & 0,3 & 21 & 84 & $-2,8$ & 1,6 & $-0,4$ & 0,1 & $-0,1$ & 0,1 & 0,1 & 4 & 16 & $-35,0$ & $-1,6$ & $-1,6$ & 1,0 & 0,1 & 0,2 & 1,2 & 1,3 & 0,3 & 6,3 & 0,83 & 0,22 & 4,03 \\
\hline b. B $2000-0$ a 1000 & 19 & $-5,4$ & $-2,2$ & $-0,4$ & 0,2 & 0,1 & 0,0 & 0,3 & 16 & 84 & $-1,8$ & $-1,7$ & $-0,2$ & 0,1 & 0,1 & 0,0 & 0,1 & 3 & 16 & $-24,8$ & $-4,8$ & $-1,4$ & 0,7 & 0,2 & 0,2 & 1,1 & 1,4 & 0,7 & 5,3 & 0,91 & 0,44 & 3,42 \\
\hline ab. E 2003 - 0 a 1000 & 52 & $-4,7$ & $-2,3$ & $-0,9$ & 0,1 & 0,1 & 0,1 & 0,3 & 50 & 96 & $-2,3$ & $-1,6$ & $-0,8$ & 0,1 & 0,1 & 0,1 & 0,2 & 2 & 4 & $-66,0$ & $-17,7$ & $-2,8$ & 1,8 & 0,7 & 0,4 & 2,9 & 1,7 & 1,2 & 14,5 & 1,08 & 0,75 & 9,30 \\
\hline ab. F 2003 - 1001 a 2000 & 1 & $-6,0$ & 1,0 & $-1,5$ & 0,2 & 0,0 & 0,2 & 0,3 & 1 & 100 & $-6,0$ & 1,0 & $-1,5$ & 0,2 & 0,0 & 0,2 & 0,3 & 0 & 0 & - & - & - & - & - & - & - & 1,7 & 1,7 & - & 1,09 & 1,09 & - \\
\hline ab. D 2005 - 0 a 1000 & 185 & $-14,0$ & $-0,9$ & $-0,3$ & 0,4 & 0,0 & 0,0 & 0,5 & 113 & 61 & $-0,3$ & 0,5 & 0,7 & 0,0 & 0,0 & $-0,1$ & $-0,1$ & 72 & 39 & $-35,7$ & $-3,1$ & $-1,8$ & 1,0 & 0,1 & 0,2 & 1,3 & 2,3 & $-0,5$ & 6,8 & 1,48 & $-0,35$ & 4,35 \\
\hline b. E $2003-1001$ a 2000 & 17 & $-14,3$ & $-2,7$ & $-0,3$ & 0,4 & 0,1 & 0,0 & 0,5 & 14 & 82 & $-2,0$ & $-2,0$ & $-0,5$ & 0,1 & 0,1 & 0,1 & 0,2 & 3 & 18 & $-71,5$ & $-5,8$ & 0,8 & 2,0 & 0,2 & $-0,1$ & 2,1 & 2,7 & 1,0 & 10,6 & 1,73 & 0,64 & 6,81 \\
\hline o. F 2001 - 0 a 1000 & 15 & $-11,7$ & $-1,0$ & $-1,8$ & 0,3 & 0,0 & 0,2 & 0,6 & 7 & 47 & $-6,1$ & $-0,1$ & $-1,5$ & 0,2 & 0,0 & 0,2 & 0,4 & 8 & 53 & $-16,6$ & $-1,9$ & $-2,1$ & 0,5 & 0,1 & 0,3 & 0,8 & 3,0 & 1,9 & 4,1 & 1,96 & 1,21 & 2,61 \\
\hline O. E 2002 - 1001 a 2000 & 27 & $-14,2$ & $-2,1$ & $-1,3$ & 0,4 & 0,1 & 0,2 & 0,6 & 17 & 63 & $-1,2$ & $-1,7$ & $-1,5$ & 0,0 & 0,1 & 0,2 & 0,3 & 10 & 37 & $-36,4$ & $-2,8$ & $-1,1$ & 1,0 & 0,1 & 0,1 & 1,3 & 3,3 & 1,5 & 6,3 & 2,11 & 0,96 & 4,06 \\
\hline D. A 1998 - acima de 2001 & 20 & $-16,4$ & $-5,4$ & $-0,7$ & 0,5 & 0,2 & 0,1 & 0,7 & 15 & 75 & $-1,0$ & 0,6 & $-0,7$ & 0,0 & 0,0 & 0,1 & 0,1 & 5 & 25 & $-62,7$ & $-23,5$ & $-0,4$ & 1,7 & 0,9 & 0,1 & 2,7 & 3,8 & 0,5 & 13,5 & 2,43 & 0,34 & 8,70 \\
\hline Fab. F 2001 - acima de 2001 & 6 & $-25,3$ & $-0,8$ & $-0,3$ & 0,7 & 0,0 & 0,0 & 0,8 & 2 & 33 & $-4,0$ & 1,2 & 0,8 & 0,1 & 0,0 & $-0,1$ & 0,0 & 4 & 67 & $-35,9$ & $-1,9$ & $-0,8$ & 1,0 & 0,1 & 0,1 & 1,2 & 3,9 & $-0,2$ & 5,9 & 2,48 & $-0,13$ & 3,79 \\
\hline Fab. F 2001 - 1001 a 2000 & 17 & $-10,9$ & $-1,4$ & $-3,2$ & 0,3 & 0,1 & 0,4 & 0,8 & 8 & 47 & $-3,2$ & 0,6 & $-1,2$ & 0,1 & 0,0 & 0,2 & 0,2 & 9 & 53 & $-17,7$ & $-3,1$ & $-5,0$ & 0,5 & 0,1 & 0,7 & 1,3 & 3,9 & 1,2 & 6,4 & 2,54 & 0,74 & 4,13 \\
\hline ab. B $1996-1001$ a 2000 & 8 & $-18,3$ & $-2,6$ & $-1,6$ & 0,5 & 0,1 & 0,2 & 0,8 & 5 & 63 & $-1,8$ & 0,0 & $-0,4$ & 0,0 & 0,0 & 0,0 & 0,1 & 3 & 38 & $-45,7$ & $-7,0$ & $-3,6$ & 1,3 & 0,3 & 0,5 & 2,0 & 4,1 & 0,5 & 10,2 & 2,65 & 0,32 & 6,53 \\
\hline b. A $1998-1001$ a 2000 & 31 & $-23,4$ & $-4,2$ & $-0,4$ & 0,6 & 0,2 & 0,1 & 0,9 & 19 & 61 & $-2,1$ & 0,8 & $-0,2$ & 0,1 & 0,0 & 0,0 & 0,0 & 12 & 39 & $-57,1$ & $-12,3$ & $-0,8$ & 1,6 & 0,5 & 0,1 & 2,1 & 4,3 & 0,2 & 10,9 & 2,79 & 0,15 & 6,98 \\
\hline o. C 1997 - 0 a 1000 & 10 & $-24,7$ & $-6,9$ & $-1,8$ & 0,7 & 0,3 & 0,2 & 1,2 & 5 & 50 & 4,0 & $-0,4$ & $-1,1$ & $-0,1$ & 0,0 & 0,1 & 0,1 & 5 & 50 & $-53,3$ & $-13,5$ & $-2,5$ & 1,5 & 0,5 & 0,3 & 2,3 & 6,0 & 0,3 & 11,7 & 3,84 & 0,16 & 7,52 \\
\hline o. C 1995 - 0 a 1000 & 5 & $-35,0$ & $-4,7$ & $-0,5$ & 1,0 & 0,2 & 0,1 & 1,2 & 2 & 40 & $-1,5$ & $-2,5$ & $-1,1$ & 0,0 & 0,1 & 0,2 & 0,3 & 3 & 60 & $-57,3$ & $-6,2$ & 0,0 & 1,6 & 0,2 & 0,0 & 1,8 & 6,1 & 1,5 & 9,2 & 3,93 & 0,94 & 5,92 \\
\hline ab. B $2000-1001$ a 2000 & 22 & $-24,9$ & $-12,0$ & $-1,3$ & 0,7 & 0,5 & 0,2 & 1,3 & 10 & 45 & 8,1 & $-4,3$ & $-0,5$ & $-0,2$ & 0,2 & 0,1 & 0,0 & 12 & 55 & $-52,5$ & $-18,4$ & $-2,0$ & 1,5 & 0,7 & 0,3 & 2,4 & 6,7 & 0,0 & 12,2 & 4,29 & 0,01 & 7,85 \\
\hline ab. A 1997 - acima de 2001 & 17 & $-27,5$ & $-8,6$ & $-1,8$ & 0,8 & 0,3 & 0,2 & 1,3 & 6 & 35 & $-5,8$ & 0,7 & $-0,3$ & 0,2 & 0,0 & 0,0 & 0,2 & 11 & 65 & $-39,4$ & $-13,6$ & $-2,6$ & 1,1 & 0,5 & 0,3 & 1,9 & 6,7 & 0,9 & 9,8 & 4,29 & 0,59 & 6,31 \\
\hline ab. E 2002 - 0 a 1000 & 20 & $-20,6$ & $-4,9$ & $-6,0$ & 0,6 & 0,2 & 0,8 & 1,5 & 13 & 65 & $-1,7$ & $-1,7$ & $-0,9$ & 0,0 & 0,1 & 0,1 & 0,2 & 7 & 35 & $-55,6$ & $-10,9$ & $-15,3$ & 1,5 & 0,4 & 2,0 & 4,0 & 7,8 & 1,2 & 20,1 & 5,03 & 0,76 & 12,95 \\
\hline b. C $1997-1001$ a 2000 & 12 & $-37,2$ & $-8,7$ & $-2,1$ & 1,0 & 0,3 & 0,3 & 1,6 & 4 & 33 & 2,0 & $-0,6$ & $-1,8$ & $-0,1$ & 0,0 & 0,2 & 0,2 & 8 & 67 & $-56,8$ & $-12,8$ & $-2,2$ & 1,6 & 0,5 & 0,3 & 2,3 & 8,2 & 1,0 & 11,9 & 5,30 & 0,66 & 7,62 \\
\hline ab. A $1997-0$ a 1000 & 10 & $-42,7$ & $-21,0$ & $-0,9$ & 1,2 & 0,8 & 0,1 & 2,1 & 6 & 60 & $-4,4$ & 0,7 & $-0,3$ & 0,1 & 0,0 & 0,0 & 0,1 & 4 & 40 & $-100,0$ & $-53,6$ & $-1,7$ & 2,8 & 2,0 & 0,2 & 5,0 & 10,6 & 0,7 & 25,3 & 6,78 & 0,45 & 16,28 \\
\hline b. D 1999 - 0 a 1000 & 13 & $-49,8$ & $-11,6$ & $-2,2$ & 1,4 & 0,4 & 0,3 & 2,1 & 3 & 23 & $-5,3$ & $-0,2$ & $-1,4$ & 0,1 & 0,0 & 0,2 & 0,3 & 10 & 77 & $-63,2$ & $-15,0$ & $-2,5$ & 1,8 & 0,6 & 0,3 & 2,6 & 10,7 & 1,7 & 13,4 & 6,86 & 1,10 & 8,59 \\
\hline ab. A $1997-1001$ a 2000 & 10 & $-37,0$ & $-24,3$ & $-2,6$ & 1,0 & 0,9 & 0,3 & 2,3 & 3 & 30 & $-4,2$ & $-0,7$ & $-2,2$ & 0,1 & 0,0 & 0,3 & 0,4 & 7 & 70 & $-51,1$ & $-34,4$ & $-2,7$ & 1,4 & 1,3 & 0,4 & 3,1 & 11,5 & 2,2 & 15,5 & 7,41 & 1,41 & 9,97 \\
\hline Fab. B 2000 - acima de 2001 & 21 & $-43,9$ & $-14,2$ & $-4,7$ & 1,2 & 0,5 & 0,6 & 2,4 & 4 & 19 & $-0,9$ & 0,0 & 0,7 & 0,0 & 0,0 & $-0,1$ & $-0,1$ & 17 & 81 & $-54,0$ & $-17,5$ & $-5,9$ & 1,5 & 0,7 & 0,8 & 2,9 & 12,0 & $-0,4$ & 14,9 & 7,69 & $-0,23$ & 9,56 \\
\hline ab. C 1997 - acima de 2001 & 13 & $-45,0$ & $-21,5$ & $-4,6$ & 1,2 & 0,8 & 0,6 & 2,7 & 4 & 31 & 7,1 & $-5,8$ & $-2,0$ & $-0,2$ & 0,2 & 0,3 & 0,3 & 9 & 69 & $-68,1$ & $-28,6$ & $-5,7$ & 1,9 & 1,1 & 0,8 & 3,7 & 13,4 & 1,5 & 18,8 & 8,64 & 0,94 & 12,07 \\
\hline Fab. E 2002 - acima de 2001 & 2 & $-56,5$ & $-8,5$ & $-6,3$ & 1,6 & 0,3 & 0,8 & 2,7 & 0 & 0 & - & - & - & 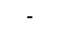 & - & - & - & 2 & 100 & $-56,5$ & $-8,5$ & $-6,3$ & 1,6 & 0,3 & 0,8 & 2,7 & 13,7 & 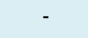 & 13,7 & 8,82 & - & 8,82 \\
\hline Fab. E 2003 - acima de 2001 & 3 & $-55,2$ & $-34,2$ & $-0,4$ & 1,5 & 1,3 & 0,0 & 2,9 & 0 & 0 & - & - & - & - & - & - & - & 3 & 100 & $-55,2$ & $-34,2$ & $-0,4$ & 1,5 & 1,3 & 0,0 & 2,9 & 14,5 & 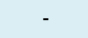 & 14,5 & 9,29 & - & 9,29 \\
\hline Fab. C 1995 - 1001 a 2000 & 10 & $-45,2$ & $-21,3$ & $-6,5$ & 1,3 & 0,8 & 0,9 & 2,9 & 3 & 30 & $-5,7$ & $-9,1$ & $-2,6$ & 0,2 & 0,3 & 0,3 & 0,8 & 7 & 70 & $-62,1$ & $-26,6$ & $-8,2$ & 1,7 & 1,0 & 1,1 & 3,8 & 14,7 & 4,3 & 19,2 & 9,48 & 2,74 & 12,36 \\
\hline ab. B 1996 - acima de 2001 & 15 & $-66,4$ & $-19,3$ & $-6,1$ & 1,8 & 0,7 & 0,8 & 3,4 & 2 & 13 & $-3,0$ & $-7,0$ & $-4,6$ & 0,1 & 0,3 & 0,6 & 0,9 & 13 & 87 & $-76,1$ & $-21,2$ & $-6,4$ & 2,1 & 0,8 & 0,8 & 3,8 & 17,1 & 4,8 & 19,0 & 10,97 & 3,08 & 12,18 \\
\hline ab. C 1995 - acima de 2001 & 12 & $-73,1$ & $-28,9$ & $-5,0$ & 2,0 & 1,1 & 0,7 & 3,8 & 2 & 17 & $-2,5$ & $-1,5$ & $-0,7$ & 0,1 & 0,1 & 0,1 & 0,2 & 10 & 83 & $-87,2$ & $-34,4$ & $-5,9$ & 2,4 & 1,3 & 0,8 & 4,5 & 19,1 & 1,1 & 22,7 & 12,25 & 0,70 & 14,57 \\
\hline ab. D $1999-1001$ a 2000 & 31 & $-67,5$ & $-37,6$ & $-5,1$ & 1,9 & 1,4 & 0,7 & 4,0 & 5 & 16 & $-3,1$ & $-2,3$ & $-1,0$ & 0,1 & 0,1 & 0,1 & 0,3 & 26 & 84 & $-79,8$ & $-44,4$ & $-5,9$ & 2,2 & 1,7 & 0,8 & 4,7 & 20,0 & 1,5 & 23,5 & 12,85 & 0,99 & 15,13 \\
\hline ab. D 1999 - acima de 2001 & 23 & $-82,5$ & $-71,0$ & $-7,1$ & 2,3 & 2,7 & 0,9 & 5,9 & 1 & 4 & $-9,5$ & $-2,0$ & 0,7 & 0,3 & 0,1 & $-0,1$ & 0,3 & 22 & 96 & $-85,8$ & $-74,2$ & $-7,5$ & 2,4 & 2,8 & 1,0 & 6,2 & 29,8 & 1,3 & 31,1 & 19,16 & 0,82 & 19,99 \\
\hline
\end{tabular}

